\title{
Ovarian pathologies in childhood
}

\author{
Halis Can Demirtürk ${ }^{1}$, Halil Ibrahim Tanriverdi ${ }^{1 *}$, Cüneyt Günşar ${ }^{1}$, Ömer Yılmaz ${ }^{1}$, Aydın Şencan ${ }^{1}$, \\ Abdülkadir Genç ${ }^{1}$, Can Taneli ${ }^{1}$ \\ ${ }^{1}$ Celal Bayar University, School of Medicine, Department of Pediatric Surgery, Manisa, Turkey.
}

Received: December 12, 2016; Accepted: January 24, 2017; Published: March 24, 2017

*Corresponding author: Halil Ibrahim Tanriverdi Celal Bayar University, School of Medicine, Department of Pediatric Surgery, Manisa, Turkey, Phone:+902362338586; Fax:+902362331466; E-mail: halilibrahimtanriverdi@gmail.com

\begin{abstract}
Introduction: Ovarian pathologies are quite often and important diseases in childhood. Most of them are benign lesions. In this study, the cases operated for ovarian pathologies are presented.

Material and method: The hospital records of female patients operated for ovarian pathologies between 2004-2016 in our clinic's are analyzed retrospectively and demographical data, pathologies and clinical findings are evaluated.

Results: Fifty-nine female patients aged from 1 month to 18 years old, were operated due to ovarian pathologies. 28 patients have been operated due to ovarian cyst. Percutaneus drainage was applied due to ovarian cyst in two patients. Para ovarian cyst was detected and excised in one patient otherwise. Ovarian torsion has been detected in 19 patients. Except those, teratoma without torsion has been detected in 9 patients.

Conclusion: Ovarian lesions are not uncommon pathologies in girls. The approach on ovarian lesions changes according to size of pathology, clinical and radiological findings. The ovary-sparing surgery should be performed and minimal invasive procedures should be preferred as long as possible.
\end{abstract}

Keywords: Ovarian pathologies; children; surger

\section{Introduction}

Adnexal masses of children are 1-2\% of all masses seen around this age group and $60-70 \%$ of these are ovarian origined. Most of adnexal masses are benign [1, 2, 3, 4, 5]. Frequency of malign or benign ovarian masses among girls lesser than 15 years old is 2.6/100000 [5]. Ovarian tumors reach the peak point around 10-14 years. Frequency of ovarian lesions increase with aging. Frequency of different histological types also differs with ageing. In this study, the cases operated for ovarian pathologies are presented.

\section{Material and method}

The hospital records of female patients operated for ovarian pathologies between 2004-2016 in our clinic are analyzed retrospectively and demographical data, pathologies and clinical findings are evaluated. Complaints of the patients, physical examination findings, evaluation of imaging techniques, levels of blood tumor markers, operation techniques and operation findings were recorded. Ovarian lesions were determined with a clinical complaint such abdominal pain or were determined incidentally. Also abdominal mass was determined in various patients on physical examination. Additionally imaging techniques such Computerized Tomography (CT) and Magnetic Resonance Imaging (MRI) were done except Ultrasonography (US). Also blood levels of Alpha Fetoprotein (AFP) and Betahuman Chorionic Gonadotropin (B-hCG) as tumor markers were evaluated. The operations were performed with laparoscopy or laparotomy. Also percutaneous drainage was applied with US. The ovarian lesions were noted as cyst or solid mass. Also side and diameters of lesions, additional pathologies were recorded. It was noted that torsion was accompanied or not to the lesion. Cyst excision, ovary-sparing surgery or oopherectomy were performed as surgical modality.

\section{Results}

Total of 59 female patients aged from 1 month to 18 years old, were operated due to ovarian pathologies in our clinic between 2004-2016. The ovarian lesion was located on the right side in 35 cases, located on left side in 21 cases and located bilateraly in three cases. 46 patients had applied with the abdominal pain; on the other hand the pathologies were determined incidentally in 13 patients. The abdominal mass was palpated in 18 patients. US was done to every patient, meanwhile CT was applied on 8 patients, MRI on 15 patients, BT and MRI on 3 patients. In 34patients, AFP and B-hCG were measured, which, in 2 of them, were determined higher than normal. Conventional laparotomy was performed in 35 patients and laparoscopy was performed in 22 patients, also percutaneous drainage was applied to two patients.

Twenty-eight patients have been operated due to ovarian cyst, in 22 patient's cyst excision and in 5 patient's oopherectomy have been applied. The ovarian cysts were larger than $5 \mathrm{~cm}$ diameter in all of the patients operated. A mucinous cyst adenoma has been detected in one of these. Also, percutaneus drainage was applied due to ovarian cyst in two patients. Para ovarian cyst was detected and excised in one patient otherwise. Ovarian torsion has been detected in 19 patients (Figure 1). Distortion was applied to 10 of them while oopherectomy was performed to 9 others. Whilst in 6 of 19 torsion patients, the underlying 
pathology was cyst and in one other patient, a teratoma was detected. In remaining 12 patients, no underlying pathology has been determined. Fixation was done after distortion in 6 patients. Except those, teratoma without torsion has been detected in 9 patients which all undergone ovary-sparing surgery (Figure 2). Immature teratoma was determined in one of the patients while mature teratoma was determined in the rest of patients.

\section{Discussion}

Although ovarian masses can be determined in all of childhood period, the frequency and risk of malignancy are increased with aging. Despite all these, the risk of malignancy in children is extremely low [7]. In our patients, the age distribution was also wide (From 1 month to 18 years old) and the malignancy incidence was very low. Benign pathologies were diagnosed in almost all our cases. The most common ovarian pathologies are cysts, and most of them are benign. The most common of neo plastic ovarian pathologies is germ-cell tumors and teratomas are the most common subgroup of them $[5,6]$. The vast majority of our patients were benign ovarian cysts, as the most of neo plastic masses we detected were teratomas. In one case a mucinous cyst adenoma was found and an immature teratoma in one another, these patients were followed up without any problem.

Because pelvis in children is rather smaller and ovaries are

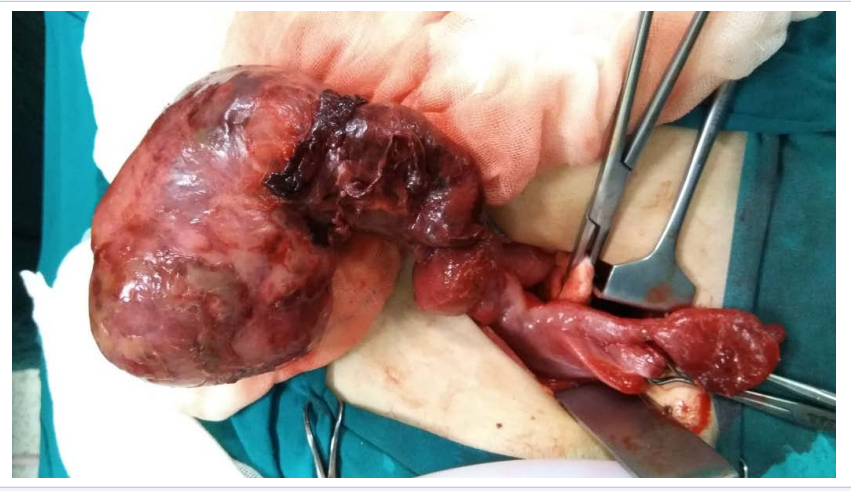

Figure 1: Ovarian torsion in a 17-years old girl.

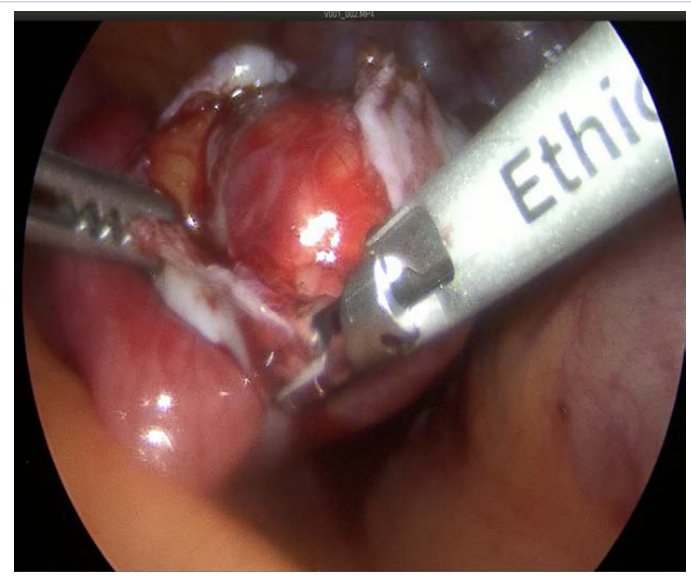

Figure 2: Ovarian teratoma in a 14-years old girl located on rather upper side, symptoms are present in the earlier stages compared with adults $[1,8]$. As many various symptoms can be seen, the most common of them is abdominal pain. The pain is usually due to complications [9]. Torsion, haemorrhage or rupture due to mass can cause acute abdomen presentation $[4,5$, $6,10]$. The pain may present in a more chronicle way, especially with abdominal distension. Anorexia, nausea, vomiting, urgency are other symptoms. Acute abdominal pain was the first finding in most of our patients. In approximately a quarter of patients, abdominal mass was incidentally detected. The frequencies of incidentally detected masses are increasing. The spread and increasingly frequent usage of US is an effective factor in this condition. During physical examination, a tender abdominal mass may be palpated in $60 \%$ of patients. These masses are usually mobile and palpated in pelvic region. An abdominal mass was palpated in about one third of our patients.

AFP andB-hCG are two important markers of diagnosis and follow-up of ovarian pathologies in childhood [5, 7, 10, 11]. In children, AFP and B-hCG are more sensitive than other tumor markers. The sensitivity and specificity of CA125 is lesser than adults. Tumor markers are not specific to indicate the malinancy. Therefore, we evaluated our patients according to AFP and B-hCG and found out high levels in very few of them.

For the diagnosis of ovarian pathologies, the role of US is very major. Also, in determination of whether the mass is solid or cystic or in evaluation of ovarian blood flow and torsion, US and Doppler US are efficient [5]. CT and MRI supplies more detailed information about the location and inner structure of the mass [3]. For this reason, we have made an ultrasonographic evaluation in all of our patients as we also used CT and MRI, especially, to evaluate the masses containing complicated and solid areas.

In children, treatments of ovarian masses are planned according to clinical, laboratory and radiological findings [2]. Ovarian mass patients are frequently misdiagnosed with acute appendicitis [9, 12]. Ovary-sparing surgery is recommended for preservation of fertility and hormonal functions [12]. Even a small portion of ovarian tissue is reported to provide fertility [6]. Ovarian masses may be excised by laparoscopy or, in larger masses, by laparotomy. Hence, we carried out lapartotomy and, particularly by our deepening experience of it, laparoscopic exploration on our cases in last period.

The treatment of pure cystic ovarian masses is planned in accordance with size of cyst, symptoms and risk of torsion. The masses containing septa, debris and solid areas are excised due to their risk of malignancy careless of their size and clinical presentation. The widespread opinion about ovarion lesions is operative exploration for all masses larger than $5 \mathrm{~cm}$-diameter and the masses smaller than $5 \mathrm{~cm}$-diameter with septation or solid components [4]. In patients of the simple ovarian masses larger than $5 \mathrm{~cm}$-diameter US-guided percutaneous aspiration or laparoscopic aspiration of cyst, unroofing or cyst excition may be applied $[4,13]$. In patients of solid, complex of masses careless of size, in patients of cystic masses larger than $5 \mathrm{~cm}$-diameter surgical interference should be applied [4]. We also have applied 
surgical exploration on whole of the patient's detected overian cyst with a larger size than $5 \mathrm{~cm}$-diameters. Only two patients of simple ovarian cyst have been applied with percutaneous drainage and no recurrence occurred afterwards. All the patients complicated and containing solid components are explorated operatively careless of their size. In presence of malignancy, biopsy sampling on the counterpart ovary and peritoneum, peritoneal lavage, omentectomy, retroperitoneal biopsy, pelvic biopsy, periaortic lymph node biopsy should be done [6].

Ovarian torsions may appear on the ovarian cyst or ovarian mass ground. Due to risk of malignancy of the mass caused ovarian torsion and systemic effects of necrotic tissue, torsioned ovary with a restraint blood supply is treated with oopherectomy [7]. However, in the purpose of preserving the fertility, ovarysparing methods are trended up recently $[8,14,15]$. In the recent period, even for the ovaries with necrotic appearances, oopherectomy is abstained $[16,17]$. Torsion may occur without any other pathology in ovaries. The risk of development of torsion is increases with the sizing up of cyst or mass. In addition, as benign lesions are more likely to be mobile than the maligns, the risk of development of torsion increases [16]. Our numbers of oopherectomy surgery was high, however, most of them were our older dated patients and in more recent patients we also leave the ovary.

Consequently, ovarian lesions are not uncommon pathologies in girls and not all might be symptomatic. The approach on ovarian lesions changes according to size of pathology, clinical and radiological findings. The female patients applied with abdominal pain should be considered carefully with US for ovarian pathologies. Torsion should be considered particularly for acute abdomen patients. Care should be taken due to failure of the organ. The risk of malign lesions presence should not be neglected though very rare it is. The ovary-sparing surgery should be performed and minimal invasive procedures should be preferred as long as possible.

\section{References}

1. Schultz KA, Ness KK, Nagarajan R, Steiner ME. Adnexal masses in infancy and childhood. Clin Obstet Gynecol. 2006;49(3):464-479.

2. Piippo S, Mustaniemi L, Lenko H, Aine R, Mäenpää J. Surgery for ovarian masses during childhood and adolescence: a report of 79 cases. J Pediatr Adolesc Gynecol. 1999;12(4):223-227.
3. Templeman CL, Fallat ME. Benign ovarian masses. Semin Pediatr Surg. 2005;14(2):93-99. Doi:http://dx.doi.org/10.1053/j.sempedsurg.2005.01.004.

4. Grabowski A, Korlacki W, Pasierbek M. Laparoscopy in elective and emergency management of ovarian pathology in children and adolescents. Videosurgery Mini- inv. 2014;9:164-169. doi:10.5114/ wiitm.2014.41626.

5. Von Allmen D, Fallat ME. Ovarian Tumors.Pediatric Surgery, Coran AG. 7th Ed, Elsevier Saunders, Philedelphia. 2012;pp.529-548.

6. Başaklar AC. Over tümör ve Kistleri. Cilt 2, Bölüm 87. Bebek ve Çocukların Cerrahi ve Ürolojik Hastalıkları. Palme Yayıncılık, Ankara. 2006,s.2041-2059.

7. Oltmann SC, Garcia N, Barber R, Huang R, Hicks B, Fischer A. Can we preoperatively risk stratify ovarian masses for malignancy? J Pediatr Surg. 2010;45(1):130-134. doi:10.1016/j.jpedsurg.2009.10.022.

8. Fawcett SL, Gomez AC, Barter SJ, Ditchfield M, Set P. More harm than good? The anatomy of misguided shielding of the ovaries. Br J Radiol. 2012;85(1016):442-447. doi:10.1259/bjr/25742247.

9. Pomeranz AJ, Sabnis S. Misdiagnoses of ovarian masses in children and adolescents. Pediatr Emerg Care. 2004;20(3):172-174.

10. Papic JC, Finnell SME, Slaven JE, Billmire DF, Rescorla FJ, Leys CM. Predictors of ovarian malinancy in children: Overcoming clinical barriers of ovarian preservation. J Pediatr Surg. 2014;49:144-148. doi:10.1016/j.jpedsurg.2013.09.068.

11.Zhang M, Jiang W, Li G, Xu C. Ovarian Masses in Children and Adolescents - An Analysis of 521 Clinical Cases. J Pediatr Adolesc Gynecol. 2014;27(3):e73-e77. doi:10.1016/j.jpag.2013.07.007.

12. Hayes-Jordan A. Surgical management of the incidentally identified ovarian mass. Semin Pediatr Surg. 2005;14(2):106-110.

13. Ateş O, Karakaya E, Hakgüder G, Olguner M, Seçil M, Akgür FM. Laparoscopic excision of a giant ovarian cyst after ultrasound-guided drainage. J Pediatr Surg. 2006;4:E9-11.

14. Loh AH, Ong CL, Lam SL, Chua JH, Chui CH. Pediatric risk of malignancy index for preoperative evaluation of childhood ovarian tumors. Pediatr Surg Int. 2012;28(3):259-266.

15. Celik A, Ergün O, Aldemir H, Ozcan C, Ozok G, Erdener A ve ark. Long-term results of conservative management of adnexal torsion in children. J Pediatr Surg. 2005; 40(4):704-708.

16. Cass DL. Ovarian Torsion. Seminars in Pediatric Surgery. 2005;14(2):86-92.

17. Geimanaite L, Trainavicius K. Ovarian torsion in children: Management and outcomes. J Pediatr Surg. 2013;48:1946-1953. doi:10.1016/j. jpedsurg.2013.04.026. 